Kexun Chen, Jiawei Zha, Fenqin Hu, Xiaoya Ye, Shuai Zou, Ville Vähänissi, Joshua M.Pearce, Hele Savin, Xiaodong Su, MACE nano-texture process applicable for both single- and multi-crystalline diamond-wire sawn Si solar cells. Solar Energy Materials and Solar Cells191, March 2019, pp. 1-8. https://doi.org/10.1016/i.solmat.2018.10.015

\title{
MACE nano-texture process applicable for both single- and multi- crystalline diamond-wire sawn Si solar cells
}

\author{
Kexun Chen ${ }^{1,2}$, Jiawei Zha ${ }^{1}$, Fenqin $\mathrm{Hu}^{1}$, Xiaoya $\mathrm{Ye}^{1}$, Shuai Zou ${ }^{1}$, Ville Vähänissi², Joshua M. \\ Pearce $^{2,3}$, Hele Savin ${ }^{2}$, Xiaodong $\mathrm{Su}^{1 *}$
}

1. School of Physical Science and Technology, Collaborative Innovation Center of Suzhou Nano Science and Technology, and Jiangsu Key Laboratory of Thin Films, Soochow University, 1 Shizi street, Suzhou 215006, China

2. Aalto University, Department of Electronics and Nanoengineering, Tietotie 3, 02150 Espoo, Finland

3. Department of Materials Science \& Engineering and Department of Electrical \& Computer

Engineering, Michigan Technological University, Houghton, MI 49931 USA.

* Correspondence Author: Phone: +86 512 69157039, e-mail: xdsu@suda.edu.cn

\begin{abstract}
The photovoltaic (PV) industry requires efficient cutting of large single and multi-crystalline (sc- and mc-) silicon (Si) wafers. Historically multi-wire slurry sawing (MWSS) dominated, but the higher productivity of diamond-wire-sawing (DWS) holds promise for decreasing PV costs in the future. While surface texturing of DWS wafers is more complicated than of MWSS wafers, especially in mcSi wafers, nanotexturing has been shown to overcome this challenge. While the benefit of nanotexturing is thus clearer in mc-Si, a universal nano-texture process that also works on sc-Si would simplify and reduce the investments costs of PV production-lines. In this paper, such a nano-texture process is developed using a metal-assisted chemical etch (MACE) technique. Step-by-step characterization of surface structure and reflectance of the MACE process is used after: 1) wafering, 2) standard acidic texturing etch, 3) silver nanoparticles deposition, and 4) MACE nanotexturing for both sc and mc-Si. The results show that the same MACE process works effectively for both sc-Si and mcSi wafers. Finally, the nano-textured wafers are processed into PV cells in an industrial process line with conversion efficiencies of $19.4 \%$ and $18.7 \%$, for sc-Si and mc-Si solar cells, respectively.
\end{abstract}

Keywords: black silicon; black Si solar cell; metal-catalyzed chemical etching; metal-assisted chemical etching; Micro-texture; Nano-texture

\section{Introduction}

The photovoltaic (PV) industry is made up of over $90 \%$ traditional single crystalline (sc) and multi-crystalline (mc) silicon ( $\mathrm{Si}$ ) wafer-based devices ${ }^{1}$. Thus, current PV production requires efficient wafering of large Si ingots. This has historically been done with the now well-established multi-wire slurry sawing (MWSS) technology ${ }^{2}$, which has almost no restrictions on the size of the Si ingots ${ }^{3}$. Additionally, for both MWSS sc-Si and mc-Si wafers, there are also well-established surface texturing processes available. The current industry standards are an alkali-based process for MWSS sc-Si ${ }^{4,5,6}$ and an acid-based process for MWSS mc-Si ${ }^{7,8,9,10}$, the latter of which relies heavily on the formation of thick saw damage on the mc-Si wafer surface during the MWSS process ${ }^{11,12}$.

Recently, many advances in wafering technology have been made ${ }^{13,14,15}$ resulting in technique gaining prominence in industry known as diamond wire sawing (DWS). In comparison to MWSS, 
Kexun Chen, Jiawei Zha, Fenqin Hu, Xiaoya Ye, Shuai Zou, Ville Vähänissi, Joshua M.Pearce, Hele Savin, Xiaodong Su, MACE nano-texture process applicable for both single- and multi-crystalline diamond-wire sawn Si solar cells. Solar Energy Materials and Solar Cells191, March 2019, pp. 1-8. https://doi.org/10.1016/i.solmat.2018.10.015

DWS has many superior features: i) a relatively much higher wafer cutting efficiency (roughly 2-3 $\times$ faster) ${ }^{9}$, ii) much less waste of highly purified Si from kerf loss and environmental pollution ${ }^{16}$, and iii) no thick damaged layers on both sides of the wafer ${ }^{11}$. With DWS thinner Si wafers can be made to adapt to the developments of the PV industry ${ }^{10}$ and it eliminates the need for expensive slurry and the concomitant handling challenges ${ }^{9}$. DWS also significantly reduces the thickness and the density of saw damage resulting only in shallow saw marks near the surface. From the point-of-view of wafer quality (i.e. minority carrier lifetime), the significantly reduced saw damage is a desired feature. However, this also makes the texturing of DWS wafers much more complicated than MWSS wafers. While the lack of deep and dense saw damage is not an issue in sc-Si wafers that use alkaline texturing ${ }^{17}$, mc-Si texturing using the standard anisotropic acidic micro-texturing process is not applicable as it is known to require deep saw damage to be effective $e^{6,8,18}$. In addition, due to the difference between the acidic and alkaline micro-texturing processes, the equipment used for sc-Si and mc-Si are different. Thus, a simple and universal process for the texturing independent of the thickness of saw damage layers for DWS-processed sc-Si and mc-Si would be a significant benefit for the PV industry.

One potential solution to overcome this texturing problem is to fabricate a nanostructure on the wafer surface. This nanostructure is commonly called "black silicon" (b-Si) because of the outstanding ability to enhance light absorption rendering the surface visibly black ${ }^{19,20,21,22,23,24}$. High-quality b-Si can be produced by laser texturing ${ }^{25,26,27,28}$ and reactive ion etching (RIE) $2930,3132,33,3435$. For example, a b-Si solar cell with interdigitated back-contacts has achieved over $22 \%$ efficiency with the use of an appropriate atomic layer deposition (ALD) passivation of a cryogenically deep reactive ion etched black silicon surface ${ }^{36}$. In comparison to such complex techniques, the wet metal-assisted chemical

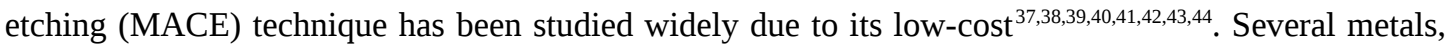
such as gold $(\mathrm{Au})^{28}$, platinum $(\mathrm{Pt})^{45,46,47}$, silver $(\mathrm{Ag})^{48,49,50,51,52}$ and copper $(\mathrm{Cu})^{53,54,55}$, have been successfully used in MACE (also called MCCE for metal catalyzed chemical etching ${ }^{56}$ ). The metal catalysts can be deposited by a number of techniques including sputtering ${ }^{57}$, electrochemical deposition $^{58,}$ evaporation ${ }^{59,60}$ and electro-less displacement ${ }^{61}$. MACE-based b-Si nanotexturing has been used e.g. since 2014 in MWSS mc-Si solar cell mass production by Canadian Solar Inc. (CSI) in Suzhou ${ }^{62,63}$.

There is some initial data indicating that the same nanotexturing methods used for b-Si formation could be effective with both MWSS and DWS mc-Si wafers. In previous studies, Ag was used in a MACE process that resulted in an 18.45\%-efficient MWSS mc-Si sol ar cell ${ }^{44}$ and an 18.32\%-efficient DWS mc-Si solar cell ${ }^{45}$. However, there has been less intensive investigation of nanotexturing on higher performing sc-Si solar cells. Oh et al. reported an $18.2 \%$ efficiency ${ }^{64}$, which is much lower than that of routinely manufactured sc-Si solar cells (where the standard inverted pyramid structure can reduce the reflectance to acceptable levels). Even though sc-Si does not require nano-texture as alkaline works efficiently, a universal process would simplify manufacturing and reduce PV costs. Here the potential of a simple MACE nanotexturing process for both sc-Si and mc-Si DWS wafers is systematically investigated. After each step of 1) wafering, 2) standard acidic micro-texturing etch, 3) Ag nanoparticles deposition and 4) MACE nanotexturing, each type of wafer (DWS sc-Si and mc-Si) is characterized for microstructure and reflectance. Finally, the MACE nano-textured wafers are processed into PV cells and their device performances are measured and reported. The primary novel contribution to this work is to demonstrate a MACE process that works effectively for both sc-Si and 
Kexun Chen, Jiawei Zha, Fenqin Hu, Xiaoya Ye, Shuai Zou, Ville Vähänissi, Joshua M.Pearce, Hele Savin, Xiaodong Su, MACE nano-texture process applicable for both single- and multi-crystalline diamond-wire sawn Si solar cells. Solar Energy Materials and Solar Cells191, March 2019, pp. 1-8. https://doi.org/10.1016/i.solmat.2018.10.015

mc-Si wafers to make high efficiency Si solar cells.

\section{Methods}

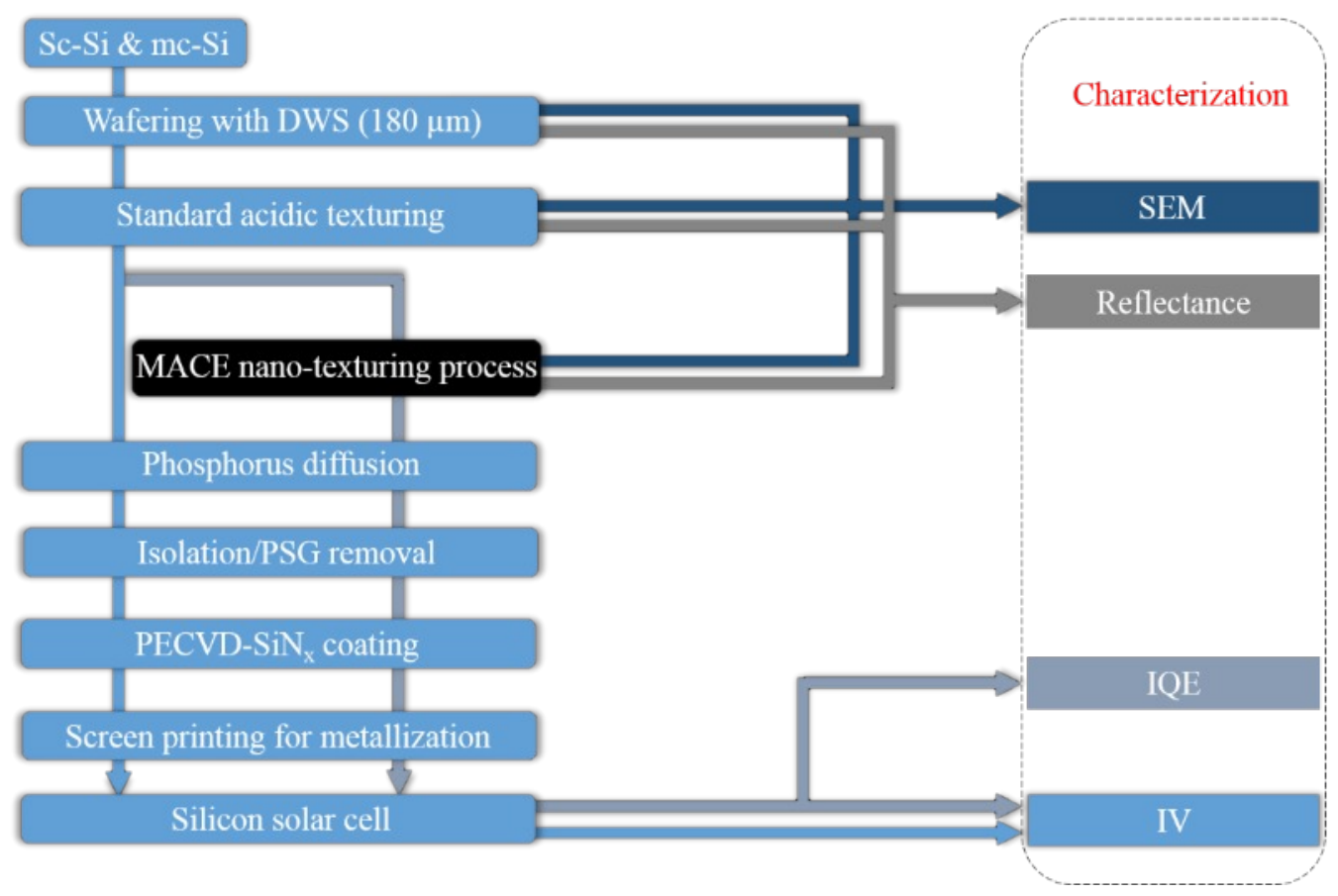

Figure 1. Experimental procedure.

The complete experimental procedure for this study, including individual processing and characterization steps, is outlined in Fig. 1. Both sc-Si (with crystal orientation (100)) and mc-Si wafers were used in the experiments. The wafers were of the standard $156 \times 156 \mathrm{~mm}^{2}$ size and the wafering was done by DWS to an initial thickness of $180 \mu \mathrm{m}$. Directly after wafering, the surface of the wafers was characterized by SEM (EBL Zeiss Supra 40) and reflectance measurements (UV-Vis-NIR Agilent Cary 5000). Next, a standard isotropic acidic texturing process in a $\mathrm{HF} / \mathrm{HNO}_{3}$ solution was applied. The resulting micro-texture was characterized by SEM and reflectance measurements. Then, the wafers experienced a MACE nanotexturing process. The MACE process consisted of three parts: i) nano-pore formation in a $\mathrm{HF}(49 \mathrm{wt} \%): \mathrm{H}_{2} \mathrm{O}_{2}(28 \mathrm{wt} \%): \mathrm{AgNO}_{3}(10 \mathrm{wt} \%): \mathrm{H}_{2} \mathrm{O}=8: 1: 0.018: 32$ solution for 5 min., ii) polishing in a $\mathrm{HF}(49 \mathrm{wt} \%): \mathrm{HNO}_{3}(69 \mathrm{wt} \%): \mathrm{H}_{2} \mathrm{O}=3: 50: 70$ solution for $30-180 \mathrm{~s}$, and iii) Ag particle removal in $69 \% \mathrm{HNO}_{3}$ solution for 6 min followed by etching in $4 \% \mathrm{HF}$ solution and rinsing in de-ionized water, all under room temperature. After the processes, the results were characterized by SEM and reflectance measurements.

To better understand the MACE nanotexturing process and its applicability on DWS wafers, an additional Ag nanoparticle deposition experiment was also performed after the standard acidic texturing. In this extra experiment, Ag nanoparticles were deposited on the wafers in a separate solution containing $0.0003 \mathrm{~mol} / \mathrm{L} \mathrm{AgNO}_{3}$ and the immersion time was varied from 1 to $5 \mathrm{~min}$. After the deposition, the distribution of the Ag nanoparticles on the wafer surfaces was characterized by SEM.

Finally, the micro-textured and nano-textured DWS sc-Si and mc-Si wafers were fabricated into 
Kexun Chen, Jiawei Zha, Fenqin Hu, Xiaoya Ye, Shuai Zou, Ville Vähänissi, Joshua M.Pearce, Hele Savin, Xiaodong Su, MACE nano-texture process applicable for both single- and multi-crystalline diamond-wire sawn Si solar cells. Solar Energy Materials and Solar Cells191, March 2019, pp. 1-8. https://doi.org/10.1016/i.solmat.2018.10.015

solar cells following the standard process at Canadian Solar Inc. (in Suzhou). The solar cells were characterized by internal quantum efficiency (IQE, QEX7 USA) and light current-voltage (IV, Berger PSL-SCD Germany) measurements under AM $1.5 \mathrm{G}$ and 1 sun illumination at $25^{\circ} \mathrm{C}$.

\section{Results and Discussions}

3.1 DWS and standard acidic texturing

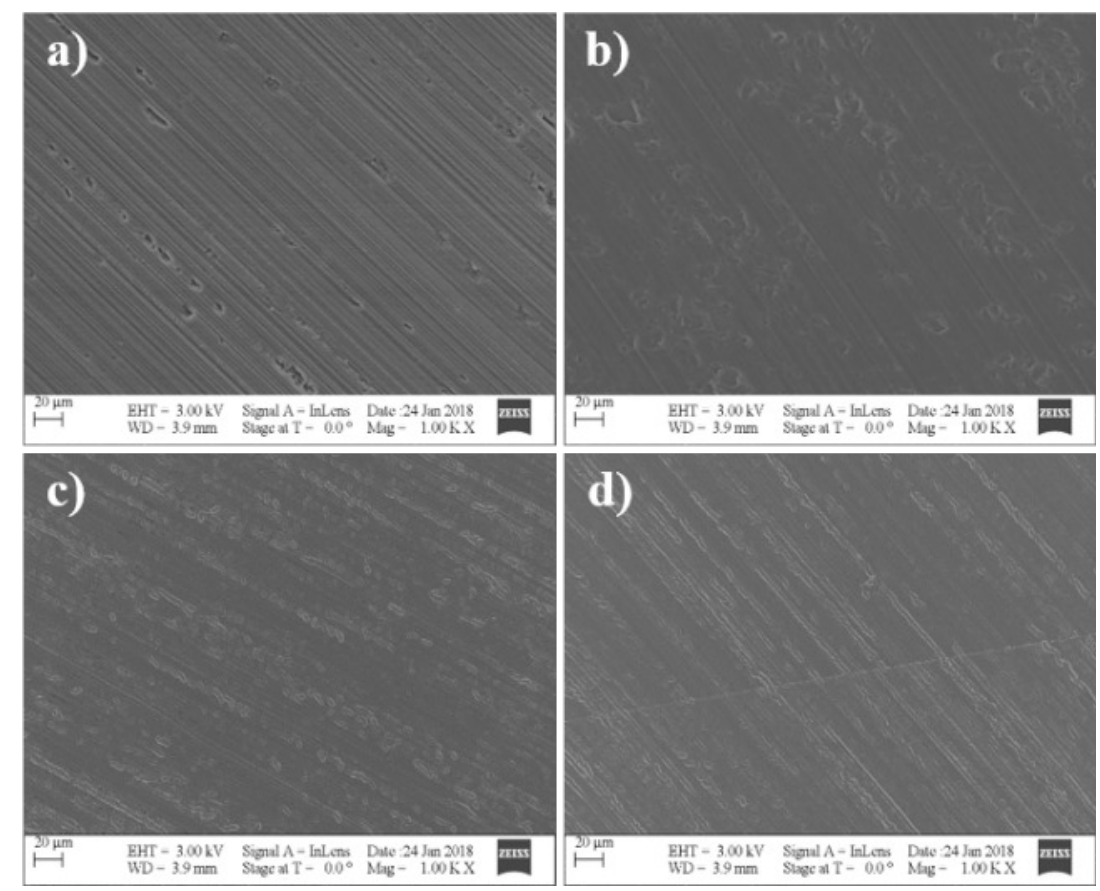

Figure 2. SEM images of the sample surfaces both directly after the DWS wafering (a) sc-Si and b) mc-Si and after applying a standard acidic micro-texturing process (c) sc-Si and d) mc-Si.

Fig. 2 shows the surface morphologies of the samples both directly after the DWS wafering and after applying a standard acidic micro-texturing process. Fig. 2. a) and b) clearly show that DWS wafers, regardless of either single or multicrystalline $\mathrm{Si}$, have a significant quantity of parallel (relatively minor) saw marks/grooves $(\sim 1-3 \mu \mathrm{m})$ and disperse pits on the surface. These are the wellknown results of DWS process ${ }^{9}$. After the standard acidic micro-texturing process, both sc-Si and mcSi surfaces have similar initial micro-oval texture of $\sim 2-3 \mu \mathrm{m}$ in width and $\sim 0.5-1 \mu \mathrm{m}$ in depth as shown in Fig. 2 c) and d). This depth can be more easily seen and is quantified in cross-sectional SEMs shown in Fig. 3. Fig. 2 also shows that deeper saw marks have a larger micro-texture size than shallower ones. However, it is also clear that (very) shallow saw marks remain on the surfaces even after micro-texturing for both materials, mainly because of the two different etching speeds between the two kinds of saw marks ${ }^{65}$. The saw damage resulting from the DWS process is clearly not enough for a standard anisotropic acidic micro-texturing process to form an acceptable antireflection layer for PV. 

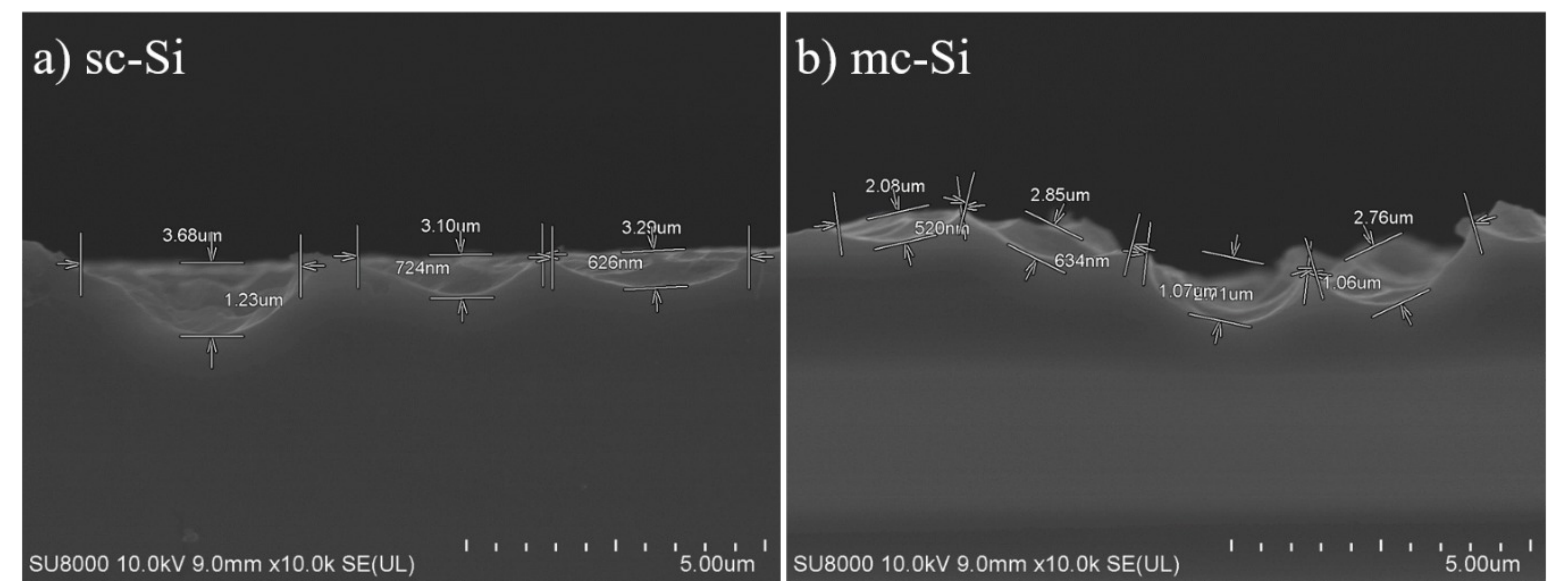

Figure 3. Cross-sectional SEM images of the sample surfaces after applying a standard acidic micro-texturing process a) sc-Si and b) mc-Si.

Fig. 4 shows the reflectance (R) as a function of wavelength $(\lambda)$ of the same samples as shown in Fig. 2 (i.e. directly after DWS wafering and after standard acidic micro-texturing). As-cut DWS sc-Si and mc-Si wafers have a similar initial reflectance. After the micro-texturing process, the average reflectance $\left(\mathrm{R}_{\mathrm{a}}\right.$ ) of DWS sc-Si and mc-Si wafers can be reduced from $33.6 \%$ to $29.0 \%$ and $34.1 \%$ to $30.3 \%$, respectively. However, it is clear, that the combination of DWS and the standard acidic microtexturing is not nearly as effective as the normal combination of MWSS sc-Si and an alkali-based process (e.g. $\mathrm{R}_{\mathrm{a}} \sim 13.0 \%$ in a wavelength range between 350 and $\left.1050 \mathrm{~nm}\right)^{47}$ or MWSS mc-Si and an acid-based process (e.g. $\mathrm{R}_{\mathrm{a}} \sim 23 \%$ in a wavelength range between 300 and $\left.900 \mathrm{~nm}\right)^{66}$. In the case of mc-Si wafers, the lack of the thick saw damage here after the DWS process can be considered as the main reason for the significantly higher reflectance. In addition, for sc-Si, the micro-oval texture on the surface resulting from this process has a higher reflectance than the inverted pyramid structure obtainable with the current alkali-based industry standard after the DWS process ${ }^{13}$. This is due to the worse surface light-trapping properties because a large part of reflected light strikes the surface only once and then escapes ${ }^{67}$. Therefore, the absorption opportunities of a photon passing through the silicon are reduced. 
Kexun Chen, Jiawei Zha, Fenqin Hu, Xiaoya Ye, Shuai Zou, Ville Vähänissi, Joshua M.Pearce, Hele Savin, Xiaodong Su, MACE nano-texture process applicable for both single- and multi-crystalline diamond-wire sawn Si solar cells. Solar Energy Materials and Solar Cells191, March 2019, pp. 1-8. https://doi.org/10.1016/i.solmat.2018.10.015

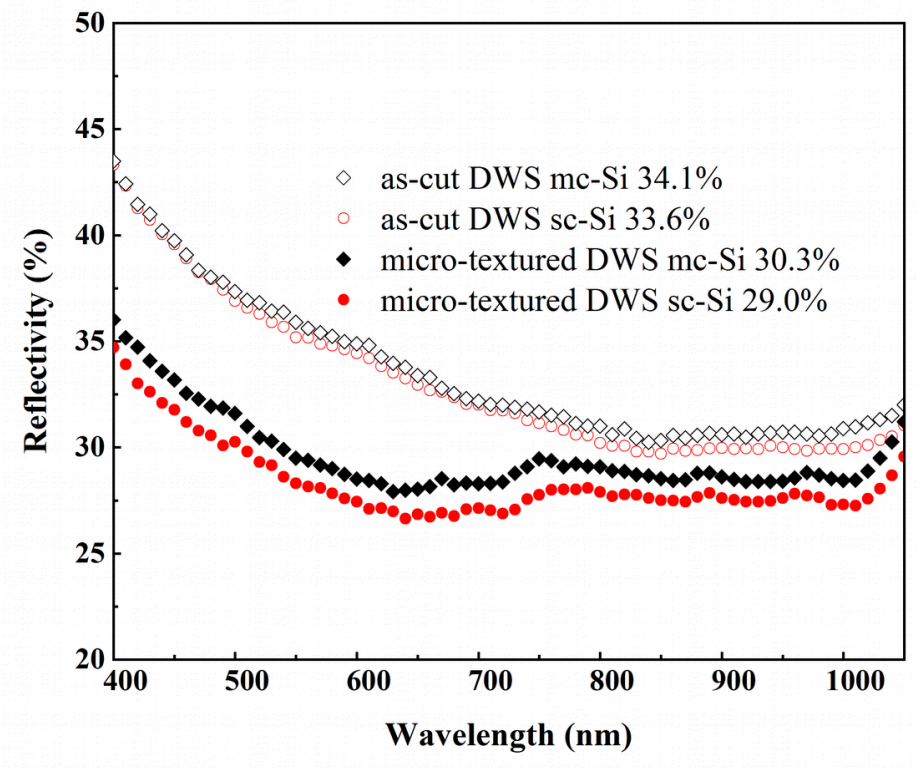

Figure 4. Reflectance curves of sc-Si and mc-Si samples directly after DWS wafering and after standard acidic micro-texturing. The average R values in a wavelength range of 400-1050 $\mathrm{nm}$ are also shown.

3.2 MACE nanotexturing

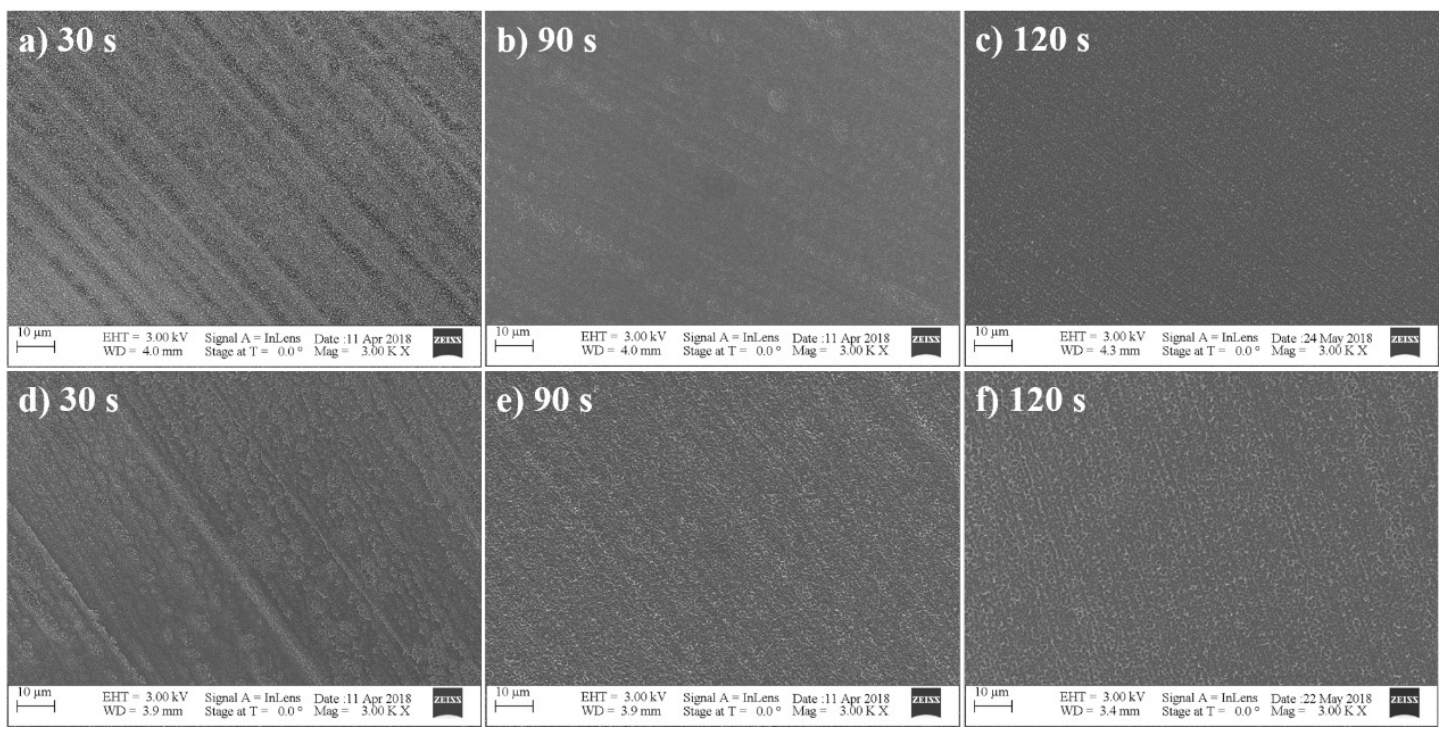

Figure 5. The surface morphologies of sc-Si (top row) and mc-Si (bottom row) wafers with different polishing times of a) and d) $30 \mathrm{~s}$; b) and e) $90 \mathrm{~s}$; c) and f) $120 \mathrm{~s}$.

Although the MACE technique can reduce the surface reflectance to $<5 \%$ for a wavelength range of $300-1000 \mathrm{~nm}$, it has been demonstrated that with conventional $\operatorname{SiN}_{\mathrm{x}}$ passivation the surface recombination will be increased due to the increasing surface area ${ }^{68}$. Thus, if novel ALD passivation schemes nullifying this problem ${ }^{69}$ are not available, an optimum in the degree of nanotexturing must be 
Kexun Chen, Jiawei Zha, Fenqin Hu, Xiaoya Ye, Shuai Zou, Ville Vähänissi, Joshua M.Pearce, Hele Savin, Xiaodong Su, MACE nano-texture process applicable for both single- and multi-crystalline diamond-wire sawn Si solar cells. Solar Energy Materials and Solar Cells191, March 2019, pp. 1-8. https://doi.org/10.1016/i.solmat.2018.10.015

found. In other words, a compromise between lowering the reflectance and increasing the surface recombination by nanostructuring has to be made. Here this was accomplished by doing additional polishing after the nano-pore formation. Fig. 5 presents SEM images of the sample surfaces obtained after the MACE nanotexturing process, a), b) and c), and d), e) and f) are taken from the surface of scSi and mc-Si wafers with different polishing times of 30 s, $90 \mathrm{~s}$ and $120 \mathrm{~s}$, correspondingly. What is interesting to notice from Fig. 4 a-c (for sc-Si) and d-f (for mc-Si) is that with the increasing polishing time, the saw marks on the surface of both sc-Si and mc-Si wafers seem to become progressively fewer and are almost completely removed after 120s (Fig. 4 c \& f). This was not the case after the conventional acidic texturing process (Fig. 2). In addition of nanostructure formation, it seems that on the contrary to mere acidic texturing, the MACE process with additional polishing would be able to also remove the microscopic saw marks and thus flatten out the wafer surface on a microscopic level. To better understand this result, an additional Ag nanoparticle deposition experiment was also performed on the DWS cut wafers Fig. 6 a), b) and c), and d), e) and f) are taken from the sc-Si and mc-Si wafer surfaces after a separate Ag nanoparticle deposition of a varying time of $60 \mathrm{~s}, 180 \mathrm{~s}$ and $300 \mathrm{~s}$, correspondingly. The molar concentration of Ag ions used is approximately equal to that in the MACE process used here. Fig. 6 reveals that the Ag nanoparticles prefer to deposit around the saw marks rather than on the flat areas. Therefore, there are more nano-pores formed in the area of the saw marks. The denser Ag nanoparticle deposition likely results from an increased amount of crystal defects distributed around those areas ${ }^{70}$. As a result, the dense nano-texture is then more easily etched in the MACE polishing step resulting in the removal of the saw marks and the flattening of the wafer surface on a microscopic level. 


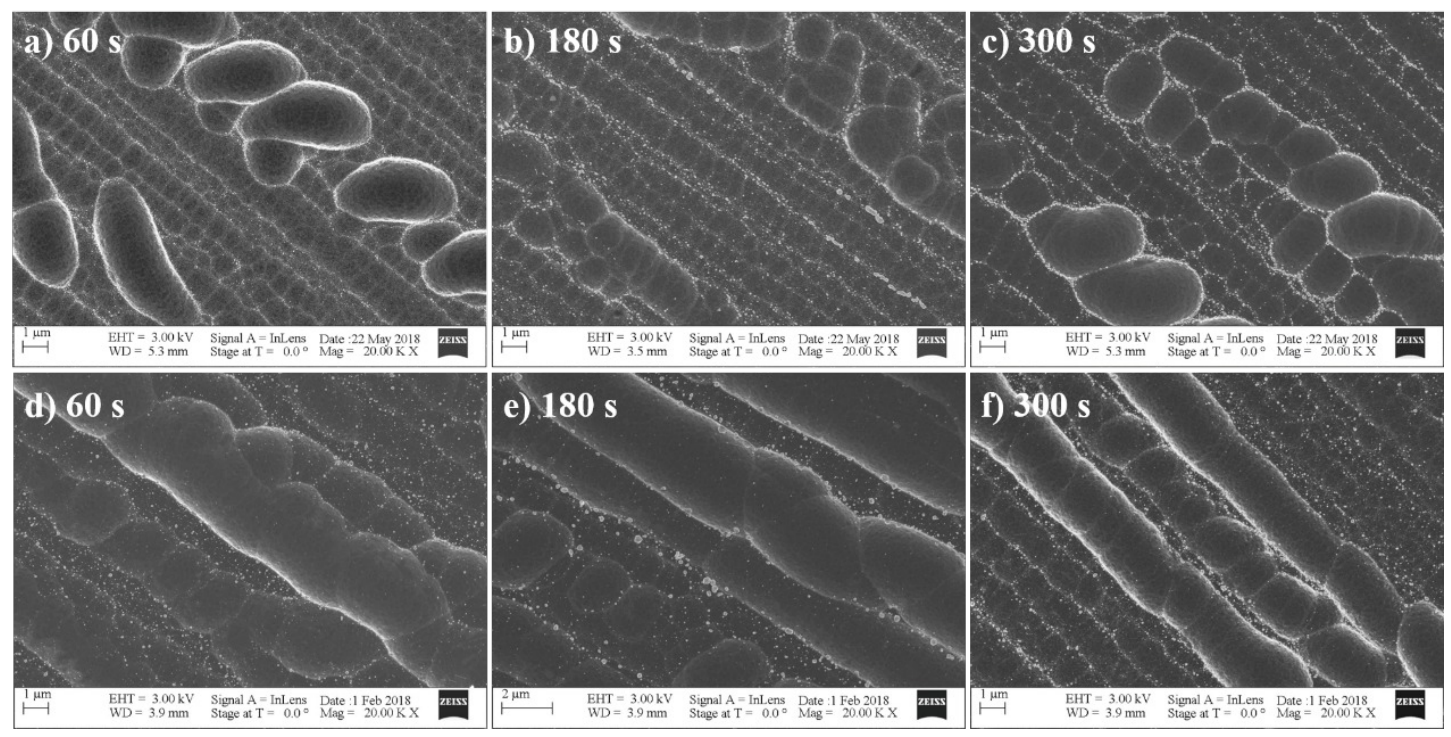

Figure 6. The distribution of Ag nanoparticles on the sc-Si (top row) and mc-Si (bottom row) wafer surfaces with different deposition times , a) and d) $60 \mathrm{~s}$, b) and e) $180 \mathrm{~s}, \mathrm{c}$ ) and f) $300 \mathrm{~s}$.

The final nano-textures of sc-Si and mc-Si were fabricated with $180 \mathrm{~s}$ and $150 \mathrm{~s}$ polishing times correspondingly and the resulting reflectivity versus wavelength curves in the wavelength range of 400$1050 \mathrm{~nm}$ after the MACE process are shown in Fig. 7. It also compares the different nano-textures for scSi and mc-Si. By increasing the polishing time, the nano-texture with wider diameter ( 950 nm) and shallower depth $(\sim 400 \mathrm{~nm})$ is obtained on the surface of the sc-Si wafer, which is different from the nano-texture obtained on the mc-Si wafer ( $720 \mathrm{~nm}$ in width and $\sim 430 \mathrm{~nm}$ in depth). In this case, after the complete MACE process, the reflectivity of DWS sc-Si and mc-Si wafers can be controlled down to $13.2 \%$ and $18.4 \%$, respectively. The achieved reflectance of $\mathrm{mc}-\mathrm{Si}$ is much lower than the conventional acid-based texturing. The results here are on a similar level as in previous work ( 18.21\% in a wavelength range of 300-1200 nm), which has been proven to provide a good cell efficiency ${ }^{38}$. However, here the fabricated nano-texture is dissimilar to the previous one that has a shallower depth ( 360 nm), but a narrower diameter $(\sim 430 \mathrm{~nm})$. This indicates that both kinds of nano-texture have a roughly equivalent ability to control light absorption in Si. For sc-Si, due to the superiority of crystal nature, the reflectivity is lower than that of mc-Si here, even if a longer polishing time was used in scSi. In addition, this kind of nano-texture of sc-Si has less surface area than mc-Si and the reflectance is comparable to that of the alkali texturing process with tetramethylammonium hydroxide (TMAH) prepolishing $(\sim 13.1 \% \text { in a wavelength range of 350-1050 } \mathrm{nm})^{47}$. 
Kexun Chen, Jiawei Zha, Fenqin Hu, Xiaoya Ye, Shuai Zou, Ville Vähänissi, Joshua M.Pearce, Hele Savin, Xiaodong Su, MACE nano-texture process applicable for both single- and multi-crystalline diamond-wire sawn Si solar cells. Solar Energy Materials and Solar Cells191, March 2019, pp. 1-8. https://doi.org/10.1016/i.solmat.2018.10.015

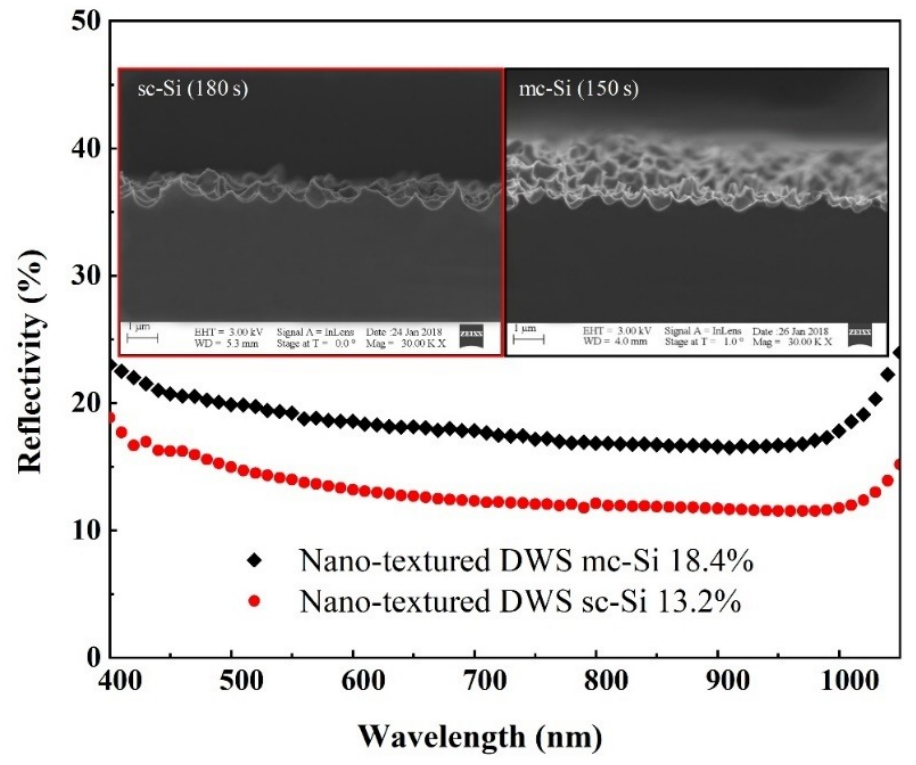

Figure 7. Reflectance of nano-textured DWS sc-Si and mc-Si wafers after the MACE process with different optimized polishing step times (i.e. $180 \mathrm{~s}$ for sc-Si and $150 \mathrm{~s}$ for mc-Si). The average R values in a wavelength range of 400-1050 $\mathrm{nm}$ are also shown. Inset: The cross-sectional SEM images of the sc-Si at $180 \mathrm{~s}$ and mc-Si at $150 \mathrm{~s}$.

\subsection{Solar cell results}

The preliminary optimization of the DWS sc-solar cells is summarized in Table 1 for polishing times of 120, 150 and 180 seconds. There may be potential to further increase the FF and efficiency by more carefully optimizing the polishing time, but this is left for future work.

Table 1. Main characteristics of DWS sc-Si solar cells with different polishing times

\begin{tabular}{|c|c|c|c|c|c|c|c|}
\hline $\begin{array}{c}\text { Polishing } \\
\text { time (s) }\end{array}$ & $\begin{array}{c}\text { Average } \\
\text { reflectance } \\
(\%)\end{array}$ & $\mathrm{V}_{\mathrm{oc}}(\mathrm{V})$ & $\mathrm{I}_{\mathrm{sc}}(\mathrm{A})$ & $\begin{array}{c}\mathrm{R}_{\mathrm{s}} \\
\left(\mathrm{m} \Omega \cdot \mathrm{cm}^{2}\right)\end{array}$ & $\begin{array}{c}\mathrm{R}_{\mathrm{sh}} \\
\left(\mathrm{k} \Omega \cdot \mathrm{cm}^{2}\right)\end{array}$ & FF (\%) & $\eta(\%)$ \\
\hline 120 & $10.2 \%$ & 0.641 & 8.991 & 413.71 & 10.91 & 80.21 & 19.04 \\
\hline 150 & $12.3 \%$ & 0.644 & 9.032 & 413.71 & 15.14 & 80.27 & 19.22 \\
\hline 180 & $13.2 \%$ & 0.643 & 9.108 & 438.05 & 27.54 & 80.34 & 19.38 \\
\hline
\end{tabular}

Fig. 8 shows the internal quantum efficiency (IQE) (ratio of the electrons collected per absorbed 
Kexun Chen, Jiawei Zha, Fenqin Hu, Xiaoya Ye, Shuai Zou, Ville Vähänissi, Joshua M.Pearce, Hele Savin, Xiaodong Su, MACE nano-texture process applicable for both single- and multi-crystalline diamond-wire sawn Si solar cells. Solar Energy Materials and Solar Cells191, March 2019, pp. 1-8. https://doi.org/10.1016/i.solmat.2018.10.015

photons) of nano-textured DWS sc-Si and mc-Si solar cells. The average IQE values in the range of 400-1050 nm are $94.24 \%$ and $92.06 \%$, respectively. A clear deviation is observed in the wavelength range from $400 \mathrm{~nm}$ to $950 \mathrm{~nm}$, which is primarily the region of visible spectrum. It appears that the

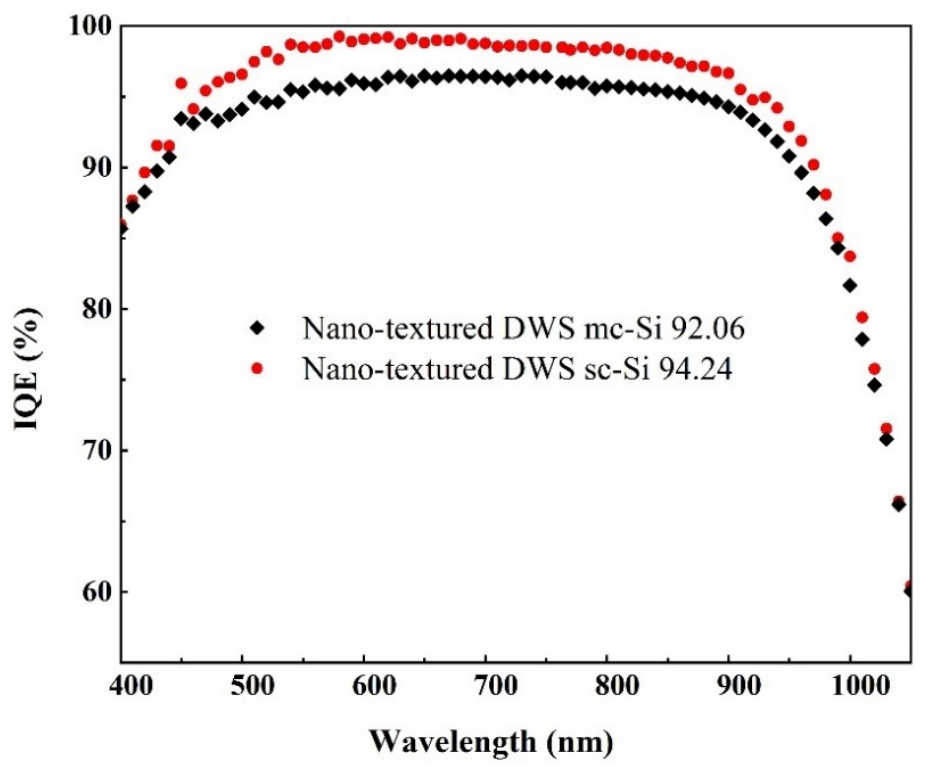

higher IQE value of sc-Si implies a lower surface recombination due to the lower density of defects, which mainly results from the comparatively flat surface situation generated by increasing the polishing time. In addition, Park et al. reported that the surface morphologies have influence on the shape of the emitter layer ${ }^{71}$. In the case of sc-Si, a larger nano-texture may allow a more homogeneous emitter layer formed during phosphorous diffusion, which will also make a contribution to the improvement of IQE than that of mc-Si. For sc-Si, IQE is only slightly lower than $94.49 \%$ obtained in the previous work ${ }^{47}$. Thus, the nano-textured sc-Si solar cells could still have a bit more potential in the short wavelengths that could be realized by modifying the structure further, although, compared with Oh et al., some progress is made here in this wavelength range at the cost of reflectance. In addition, the value of mc-Si is at same level with $92.24 \%$ obtained in previous work ${ }^{45}$. 
Kexun Chen, Jiawei Zha, Fenqin Hu, Xiaoya Ye, Shuai Zou, Ville Vähänissi, Joshua M.Pearce, Hele Savin, Xiaodong Su, MACE nano-texture process applicable for both single- and multi-crystalline diamond-wire sawn Si solar cells. Solar Energy Materials and Solar Cells191, March 2019, pp. 1-8. https://doi.org/10.1016/i.solmat.2018.10.015

Figure 8. IQE curves of nano-textured DWS sc-Si and mc-Si solar cells. The average IQE values in a wavelength range of 400-1050 $\mathrm{nm}$ are shown in the legend.

\begin{tabular}{|c|c|c|c|c|c|c|c|}
\hline \multicolumn{2}{|c|}{ Wafer type } & $\mathrm{V}_{\text {oc }}(\mathrm{V})$ & $\mathrm{I}_{\mathrm{sc}}(\mathrm{A})$ & $\begin{array}{c}\mathrm{R}_{\mathrm{s}} \\
\left(\mathrm{m} \Omega \cdot \mathrm{cm}^{2}\right)\end{array}$ & $\begin{array}{c}\mathrm{R}_{\text {sh }} \\
\left(\mathrm{k} \Omega \cdot \mathrm{cm}^{2}\right)\end{array}$ & $\mathrm{FF}(\%)$ & $\eta(\%)$ \\
\hline \multirow{2}{*}{$\begin{array}{l}\text { Micro- } \\
\text { texture }\end{array}$} & Sc-Si & 0.642 & 8.638 & 608.40 & 30.42 & 79.57 & 18.17 \\
\cline { 2 - 8 } & Mc-Si & 0.640 & 8.727 & 608.40 & 47.38 & 79.06 & 18.16 \\
\hline \multirow{2}{*}{$\begin{array}{c}\text { MACE } \\
\text { Nano- } \\
\text { texture }\end{array}$} & Sc-Si & 0.643 & 9.108 & 438.05 & 27.54 & 80.34 & 19.38 \\
\cline { 2 - 8 } & Mc-Si & 0.640 & 8.928 & 486.72 & 24.04 & 79.75 & 18.72 \\
\hline
\end{tabular}

Table 2. Main characteristics of DWS sc-Si and mc-Si solar cells

The IV-characteristics of the microtextured reference sc-Si and mc-Si solar cells and the MACE nano-textured sc-Si and mc-Si solar cells are shown in Table 2. The micro-textured DWS sc-Si and mcSi reference solar cells have a similar limited efficiency of about $18.2 \%$. As stated earlier, the DWS process does not result in thick enough saw damage for the conventional acid-based texturing to work properly. Therefore, the reference cells suffer from poor reflectance resulting in lower light absorption and lower short-circuit current $\left(\mathrm{I}_{\mathrm{sc}}\right)$. In addition, the saw marks remaining on the wafer surface after microtexturing can also lead to non-uniformity of the p-n junction and to a higher series resistance $\left(R_{s}\right)$ if the Ag fingers cross these grooves ${ }^{47}$.

Reflectance reduction and the surface morphology modification with MACE nanotexturing results in significant improvements. After nanotexturing, the efficiencies of the best nano-textured DWS sc-Si and mc-Si cells can reach $19.38 \%$ and $18.72 \%$, respectively. Both $\mathrm{I}_{\mathrm{sc}}$ values of nano-textured sc-Si and mc-Si cells are improved and $\mathrm{R}_{\mathrm{s}}$ values are also reduced. The $\mathrm{I}_{\mathrm{sc}}$ improvements can be mostly directly linked to the lower reflectance. However, the reduced $R_{s}$ values also play a role. Interestingly it seems that the removal of the microscopic saw marks has a positive effect on the $R_{s}$ values. This is in accordance with earlier results ${ }^{47}$ where a pretreatment removing the saw marks of DWS wafers was seen to have a positive effect on $\mathrm{R}_{\mathrm{s}}$. On the other hand, the introduction of nanoscale texture could result in a relevant poor contact between electrode and wafer compared with micro-textured Si solar cells, which will lead to the reduced shunt resistance $\left(\mathrm{R}_{\text {sh }}\right)$ for nano-textured $\mathrm{Si}$ solar cells. However, a larger nano-texture in the sc-Si surface should make the p-n junction and the Ag fingers more uniform and result in the lower $R_{s}$ and higher $R_{s h}$ than that of mc-Si. More importantly, because of the preliminary optimization of the nano-texture by polishing, there is no obvious decrease observed in the open-circuit voltage $\left(\mathrm{V}_{\text {oc }}\right)$ for sc-Si and mc-Si.

Overall, the results of this study are promising, as they have shown that MACE formation of nanotexture is an effective method to achieve high efficiencies of DWS for both sc-Si and mc-Si. However, MACE-based black silicon PV do not have as high of performances as dry etched black silicon PV, and future work is necessary to further refine the MACE process to develop more optimal microstructures. For example, as seen in the SEM images above, after polishing and flattening the surface, there is no longer any micro-textures on the surface. Thus, future experiments could determine if the micro- 
Kexun Chen, Jiawei Zha, Fenqin Hu, Xiaoya Ye, Shuai Zou, Ville Vähänissi, Joshua M.Pearce, Hele Savin, Xiaodong Su, MACE nano-texture process applicable for both single- and multi-crystalline diamond-wire sawn Si solar cells. Solar Energy Materials and Solar Cells191, March 2019, pp. 1-8. https://doi.org/10.1016/i.solmat.2018.10.015

texturing step might be skipped before MACE process. In addition, the highest performing black silicon devices are passivated with atomic layer deposition, which should be used to improve the performance of MACE-processed PV devices even higher. With these technical advancements there is the potential for MACE-processed black silicon to compete with the promise of dry-etched black silicon solar cells. ${ }^{72}$

\section{Conclusions}

This study has shown that this universal nanotexturing process is an effective method to overcome the lack of deep saw marks from the DWS process and create excellent light trapping structures for both sc-Si and mc-Si. Systematic characterization during the steps of the MACE process revealed the impact of nanotexturing on both types of materials. The solar energy conversion efficiency of the nanotextured DWS sc-Si and mc-Si photovoltaic cells reached the level $\sim 19.4 \%$ and $\sim 18.7 \%$, respectively. The results demonstrated that such a universal nanotexturing process has significant potential to enable high performance DWS Si wafers of either sc or mc type, thus simplifying production lines and further reducing production costs for the entire PV industry.

\section{Acknowledgements}

This work was funded by China Scholarship Council, Colleges and Universities in Jiangsu Province Plans for Graduate Research and Innovation (project No. KYZZ16_0078) and Fulbright Finland. We acknowledge the provision of facilities and technical support by Aalto University at Micronova Nanofabrication Center and OtaNano-Nanomicroscopy Center (Aalto-NMC).

\section{References}


1 Fraunhofer Institute for Solar Energy Systems ISE. Photovoltaics Report. https://www.ise.fraunhofer.de/content/dam/ise/en/documents/annual reports/Fraunhofer ISE Annual Report 2014 web final.pdf (2014).

2 H.J. Möller, C. Funke, M. Rinio, S. Scholz, Multicrystalline silicon for solar cells, Thin Solid Films 487 (2005) 179-187. https://doi.org/10.1016/j.tsf.2005.01.061.

3 H.J. Möller, Basic Mechanisms and Models of Multi-Wire Sawing, Adv. Eng. Mater. 6 (2004) 501-513. https://doi.org/10.1002/adem.200400578.

4 A.A. Fashina, K.K.Adama, O.K. Oyewole, V.C. Anye, J. Asare, M. G. Zebaze Kana, W.O. Soboyejo, Surface texture and optical properties of crystalline silicon substrates, J. Renew. Sustain. Ener. 7 (2015) 063119. https://doi.org/10.1063/1.4937117.

5 P. Campbell, M.A. Green, High performance light trapping textures for monocrystalline silicon solar cells, Sol. Energy Mater. Sol. Cells 65 (2001) 369-375. https://doi.org/10.1016/S0927-0248(00)00115-X.

6 A. Khanna, P.K. Basua, A. Filipovic, V. Shanmugam, C. Schmiga, A.G. Aberle, T. Mueller, Influence of random pyramid surface texture on silver screen-printed contact formation for monocrystalline silicon wafer solar cells, Sol. Energy Mater. Sol. Cells 132 (2015) 589-596. https://doi.org/10.1016/j.solmat.2014.10.018.

7 H.Y. Gong, M. Li, L. Zhou, A study of mottling phenomenon on textured multicrystalline silicon wafers and its potential effects on solar cell performance, Mat. Sci. Semicon. Proc. 25 (2014) 149-154. https://doi.org/10.1016/j.mssp.2014.04.029

8 U. Gangopadhyay, S.K. Dhungel, P.K. Basu, S.K. Dutta, H. Saha, J. Yi, Comparative study of different approaches of multicrystalline silicon texturing for solar cell fabrication, Sol. Energy Mater. Sol. Cells 91 (2007) 285-289. https://doi.org/10.1016/j.solmat.2006.08.011.

9 G. Kulesza, P. Panek, P. Zieba, Time efficient texturization of multicrystalline silicon in the HF/HNO3 solutions and its effect on optoelectronic parameters of solar cells, Arch. Civ. Mech. Eng. 14 (2014) 595-601. https://doi.org/10.1016/j.acme.2014.02.007.

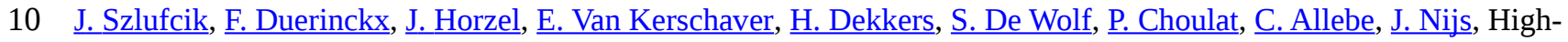
efficiency low-cost integral screen-printing multicrystalline silicon solar cells, Sol. Energy Mater. Sol. Cells 74 (2002) 155-163. https://doi.org/10.1016/S0927-0248(02)00060-0.

11 W.H. Chen, X.M. Liu, M. Li, C.Q. Yin, L. Zhou, On the nature and removal of saw marks on diamond wire sawn multicrystalline silicon wafers, Mat. Sci. Semicon. Proc. 27 (2014) 220-227. https://doi.org/10.1016/j.mssp.2014.06.049.

12 B. Meinel, T. Koschwitz, J. Acker, Textural development of SiC and diamond wire sawed sc-silicon wafer, Energy Procedia 27 (2012) 330-336. https://doi.org/10.1016/j.egypro.2012.07.072.

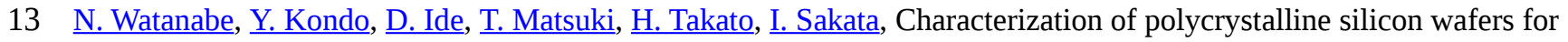
solar cells sliced with novel fixed-abrasive wire, Prog. Photovolt: Res. Appl. 18 (2010) 485-490. https://doi.org/10.1002/pip.923.

14 X.G. Yu, P. Wang, X.Q. Li, D.R. Yang, Thin Czochralski silicon solar cells based on diamond wire sawing technology, Sol. Energy Mater. Sol. Cells 98 (2012) 337-342. https://doi.org/10.1016/j.solmat.2011.11.028.

15 C. Yang, H. Wu, S. Melkote, S. Danyluk, Comparative Analysis of Fracture Strength of Slurry and Diamond Wire Sawn Multicrystalline Silicon Solar Wafers, Adv. Eng. Mater. 15 (2013) 358-365. https://doi.org/10.1002/adem.201200262.

16 A. Kumar, S.N. Melkote, Diamond Wire Sawing of Solar Silicon Wafers: A Sustainable Manufacturing Alternative to Loose Abrasive Slurry Sawing, Procedia Manufacturing 21 (2018) 549-566. https://doi.org/10.1016/j.promfg.2018.02.156.

17 E. Kayabasi, H. Kurt, E. Celik, Determination of micro sized texturing and nano sized etching procedure to enhance optical properties of n-type single crystalline silicon wafer, J. Mater. Sci: Mater. El. 28 (2017) 14085-14090. https://doi.org/10.1007/s10854-017-7260-4.

18 B. Meinel, T. Koschwitz, C. Blocks, J. Acker, Comparison of diamond wire cut and silicon carbide slurry processed silicon wafer surfaces after acidic texturisation, Mater. Sci. Semicond. Process. 26 (2014) 93-100. https://doi.org/10.1016/j.mssp.2014.03.046.

19. M. Otto, M. Algasinger, H. Branz, B. Gesemann, T. Gimpel, Black Silicon Photovoltaics, Adv. Opt. Mater. 3 (2015) 147-164. https://doi.org/10.1002/adom.201400395.

20 S. Koynov, M.S. Brandt, M. Stutzmann, Black nonreflecting silicon surfaces for solar cells, Appl. Phys. Lett. 88 (2006) 203107. https://doi.org/10.1063/1.2204573.

21 J.J. Li, J.J. Zhang, L. Fang, J.L. Wang, M.R. Shen, X.D. Su, Enhanced visible light photocatalytic properties of TiO2 thin films on the textured multicrystalline silicon wafers, J. Mater. Chem. A 3 (2015) 4903-4908. https://doi.org/10.1039/C4TA06564F. 
22 R.L. Fan, W. Dong, L. Fang, F.G. Zheng, X.D. Su, S. Zou, J. Huang, X.S. Wang, M.R. Shen, Stable and efficient multicrystalline $\mathrm{n}+\mathrm{p}$ silicon photocathode for $\mathrm{H} 2$ production with pyramid-like surface nanostructure and thin $\mathrm{Al} 2 \mathrm{O} 3$ protective layer, Appl. Phys. Lett. 106 (2015) 013902. https://doi.org/10.1063/1.4905511.

23. P. Hoyer, M. Theuer, R. Beigang, E.B. Kley, Terahertz emission from black silicon, Appl. Phys. Lett. 93 (2008) 091106. https://doi.org/10.1063/1.2978096

24 .A.M. Gouda, N.K. Allam, M.A. Swillam, Efficient fabrication methodology of wide angle black silicon for energy harvesting applications, RSC Adv. 7 (2017) 26974-26982. https://doi.org/10.1039/C7RA03568C.

25. C.H. Li, J.H. Zhao, X.Y. Yu, Q.D. Chen, J. Feng, H.B. Sun, Fabrication of Black Silicon With Thermostable Infrared Absorption by Femtosecond Laser, IEEE Photonics J. 8 (2016) 6805809. https://doi.org/10.1109/JPHOT.2016.2617403.

26 . T. H. Her, R.J. Finlay, C. Wu, S. Deliwala, E. Mazur, Microstructuring of silicon with femtosecond laser pulses, Appl. Phys. Lett. 73 (1998) 1673-1675. https://doi.org/10.1063/1.122241.

27. B.X. Zheng, W.J. Wang, G.D. Jiang, X.S. Mei, Fabrication of broadband antireflective black metal surfaces with ultra-light-trapping structures by picosecond laser texturing and chemical fluorination, Appl. Phys. B 122 (2016) 180. https://doi.org/10.1007/s00340-016-6449-1

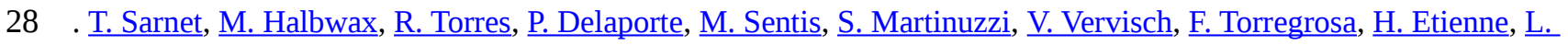
Roux, S. Bastide, Femtosecond laser for black silicon and photovoltaic cells, Proc. SPIE 6881 (2008) 688119. https://doi.org/10.1117/12.768516.

29. G. von Gastrow, R. Alcubilla, P. Ortega, M. Yli-Koski, S. Conesa-Boj, A. Fontcuberta i Morral, H. Savin, Analysis of the Atomic Layer Deposited Al2O3 field-effect passivation in black silicon, Sol. Energy Mater. Sol. Cells 142 (2015) 29-33. https://doi.org/10.1016/j.egypro.2017.09.304.

30 . J. Yoo, G. Yu, J. Yi, Large-area multicrystalline silicon solar cell fabrication using reactive ion etching (RIE), Sol. Energy Mater. Sol. Cells 95 (2011) 2-6. https://doi.org/10.1016/j.solmat.2010.03.029.

31. T. Pasanen, V.Vähänissi, N. Theut, H. Savin, Surface passivation of black silicon phosphorus emitters with atomic layer deposited SiO2/Al2O3 stacks, Energy Procedia 124 (2017) 307-312.

32 . H. Jansen, M. de Boer, R. Legtenberg, M. Elwenspoek, The black silicon method: a universal method for determining the parameter setting of a fluorine-based reactive ion etcher in deep silicon trench etching with profile control, J. Micromech. Microeng. 5 (1995) 115-120. http://dx.doi.org/10.1088/0960-1317/5/2/015.

33 . G. von Gastrow, P. Ortega, R. Alcubilla, S. Husein, T. Nietzold M. Bertoni , H. Savin, Recombination processes in passivated boron-implanted black silicon emitters, J. Appl. Phys. 121 (2017) 185706. https://doi.org/10.1063/1.4983297.

34. N. Zin, Recombination-free reactive ion etch for high efficiency silicon solar cells, Sol. Energy Mater. Sol. Cells 172

(2017) 55-58. https://doi.org/10.1016/j.solmat.2017.07.008.

35 . J.S. Yoo, I.O. Parm, U. Gangopadhyay, K. Kim, S.K. Dhungel, D.Mangalaraj, J. Yi, Black silicon layer formation for application in solar cells, Sol. Energy Mater. Sol. Cells 90 (2006) 3085-3093. https://doi.org/10.1016/j.solmat.2006.06.015.

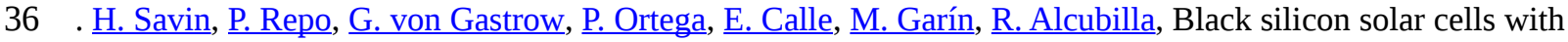
interdigitated back-contacts achieve 22.1\% efficiency, Nat. Nanotechnol. 10 (2015) 624-628. https://doi.org/10.1038/NNANO.2015.89.

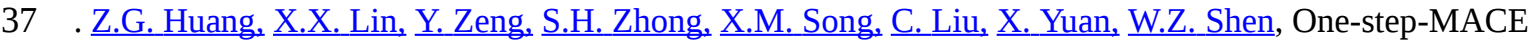
nano/microstructures for high-efficient large-size multicrystalline Si solar cells, Sol. Energy Mater. Sol. Cells 143 (2015) 302-310. https://doi.org/10.1016/j.solmat.2015.07.017.

38. H. Zheng, M.G. Han, P. Zheng, L. Zheng, H.B. Qin, L.J.Deng, Porous silicon templates prepared by Cu-assisted chemical etching, Mater. Lett. 118 (2014) 146-149. https://doi.org/10.1016/j.matlet.2013.12.093.

39 . Z.P. Huang, N. Geyer, L.F. Liu, M.Y. Li, P. Zhong, Metal-assisted electrochemical etching of silicon, Nat. Nanotechnol. 21 (2010) 465301. https://doi.org/10.1088/0957-4484/21/46/465301.

40. Z.P. Huang, N. Geyer, P. Werner, J. de Boor, U. Gösele, Metal-Assisted Chemical Etching of Silicon: A Review, Adv. Mater. 23 (2011) 285-308. https://doi.org/10.1002/adma.201001784.

41 . Z.P. Huang, N. Geyer, P. Werner, J. de Boor, U. Gösele, Metal-Assisted Chemical Etching of Silicon: A Review, Adv. Mater. 23 (2011) 285-308. https://doi.org/10.1002/adma.201001784.

42 . C.H. Hsu, J.R. Wu, Y.T. Lu, D.J. Flood, A.R. Barron, L.C. Chen, Fabrication and characteristics of black silicon for solar cell applications: An overview, Mater. Sci. Semicond. Process. 25 (2014) 2-17. 
https://doi.org/10.1016/j.mssp.2014.02.005.

43. A. Song, S. Yun, V. Lokhande, T. Ji, Rate controlled metal assisted chemical etching to fabricate vertical and uniform Si nanowires, Advanced Fabrication Technologies for Micro/nano 9759 (2016) 97591H. https://doi.org/ 10.1117/12.2212105.

44 . Y.P. Liu, T. Lai, H.L. Li, Y. Wang, Z.X. Mei, H.L. Liang, Z.L. Li, F.M. Zhang, W.J. Wang, A.Y. Kuznetsov, X.L. Du, Nanostructure Formation and Passivation of Large-Area Black Silicon for Solar Cell Applications, Small 8 (2012) 1392-1397. https://doi.org/10.1002/smll.201101792.

45 H. Han, Z.P. Huang, W. Lee, Metal-assisted chemical etching of silicon and nanotechnology applications, Nano Today 9 (2014) 271-304. https://doi.org/10.1016/j.nantod.2014.04.013.

46. E. Torralba-Penalver, S.L. Gall, R. Lachaume, Vincent Magnin, J. Harari, M. Halbwax, J.P. Vilcot, C. Cachet-Vivier, S. Bastide, Tunable Surface Structuration of Silicon by Metal Assisted Chemical Etching with Pt Nanoparticles under Electrochemical Bias, Acs Appl. Mater. Interfaces 8 (2016) 31375. https://doi.org/ 10.1021/acsami.6b09036.

47 S. Yae, Y. Kawamoto, H. Tanakaa, N. Fukumuro, H. Matsuda, Formation of porous silicon by metal particle enhanced chemical etching in HF solution and its application for efficient solar cells, Electrochem. Commun. 5 (2003) 632-636. https://doi.org/10.1016/S1388-2481(03)00146-2.

48. C. Chartier, S. Bastide, C. Lévy-Clément, Metal-assisted chemical etching of silicon in HF-H2O2, Electrochim. Acta 53 (2008) 5509-5516. https://doi.org/10.1016/j.electacta.2008.03.009.

49 H.S. Jeong, H. Song, T.H. Kim, S.W. Park, N. Lim, G.Y. Jung, Repeatable Silicon Nanowires Transfer to Flexible Substrate by Two-Step Metal Assisted Chemical Etching, Sci. Adv. Mater. 9 (2017) 184-187. https://doi.org/10.1166/sam.2017.2459.

50 R. Venkatesan, M.K. Arivalagan, V. Venkatachalapathy, J.M. Pearce, J. Mayandi, Effects of silver catalyst concentration in metal assisted chemical etching of silicon, Mater. Lett. 221 (2018) 206-210. https://doi.org/10.1016/j.matlet.2018.03.053.

51. T.N. Van, N. Inomata, M. Toda, T. Ono, Ion transport by gating voltage to nanopores produced via metal-assisted chemical etching method, Nanotechnology 29 (2018) 195301. https://doi.org/10.1088/1361-6528/aab1d3.

52 V. Sivakov, G. Andrä, A. Gawlik, A. Berger, J. Plentz, F. Falk, S.H. Christiansen, Silicon Nanowire-Based Solar Cells on Glass: Synthesis, Optical Properties, and Cell Parameters, Nano Lett. 9 (2009) 1549-1554. https://doi.org/10.1021/nl803641f.

53 Y.T. Lu, A.R. Barron, Anti-reflection layers fabricated by a one-step copper-assisted chemical etching with inverted pyramidal structures intermediate between texturing and nanopore-type black silicon, J. Mater. Chem. A 2 (2014) 12043-12052. https://doi.org/10.1039/C4TA02006E.

54 F. Toor, J. Oh, H.M. Branz, Efficient nanostructured ‘black’ silicon solar cell by copper-catalyzed metal-assisted etching, Prog. Photovolt: Res. Appl. 23 (2015) 1375-1380. https://doi.org/10.1002/pip.2562.

55 J.W. Zha, T. Wang, C.F. Pan, K.X. Chen, F.Q. Hu, X.D. Pi, X.D. Su, Constructing submicron textures on mc-Si solar cells via copper-catalyzed chemical etching, Appl. Phys. Lett. 110 (2017) 093901. https://doi.org/10.1063/1.4977191.

56 G.Z. Sheng, Y.X. Zou, S.Y. Li, W.H. Ma, Z. Ding, F.S. Xi, C. Geng, Z.D. He, Z.J. Chen, J. Yang, Y. Lei, Controllable nano-texturing of diamond wire sawing polysilicon wafers through low-cost copper catalyzed chemical etching, Mater. Lett. 221 (2018) 85-88. https://doi.org/10.1016/j.matlet.2018.03.092.

57 X. Li, P.W. Bohn, Metal-assisted chemical etching in HF/H2O2 produces porous silicon, Appl. Phys. Lett. 77 (2000) 2572-2574. https://doi.org/10.1063/1.1319191.

58 P. He, H.T. Liu, Z.Y. Li, Y. Liu, X.D. Xu, J.H. Li, Electrochemical Deposition of Silver in Room-Temperature Ionic Liquids and Its Surface-Enhanced Raman Scattering Effect, Langmuir 20 (2004) 10260-10267. https://doi.org/10.1021/la048480l.

59. W.L Syu, Y.H. Lin, A. Paliwal, K.S. Wang, T.Y. Liu, Highly sensitive and reproducible SERS substrates of bilayer Au and Ag nano-island arrays by thermal evaporation deposition, Surf. Coat. Tech. 350 (2018) 823-830.

https://doi.org/10.1016/j.surfcoat.2018.04.043.

60 H.E. Bennett, R.L. Peck, D.K. Burge, J.M. Bennett, Formation and Growth of Tarnish on Evaporated Silver Films, J. Appl. Phys. 40 (1969) 3351-3360. https://doi.org/10.1063/1.1658187.

61 V. Dřínek, M. Klementová, R. Fajgar, P. Dytrych, Silicon nanowires grown on metal substrates via self-catalyst mechanism, Mater. Lett. 160 (2015) 109-112. https://doi.org/10.1016/j.matlet.2015.07.098.

62 X.Y. Ye, S. Zou, K.X. Chen, J.J. Li, J. Huang, F. Cao, X.S. Wang, L.J. Zhang, X.F. Wang, M.R. Shen, X.D. Su, 18.45\%Efficient Multi-Crystalline silicon Solar Cells with Novel Nanoscale Pseudo-Pyramid Texture, Adv. Funct. Mater. 24 (2014) 6708-6716. https://doi.org/10.1002/adfm.201401589.

63 F. Cao, K.X. Chen, J.J. Zhang, X.Y. Ye, J.J. Li, S. Zou, X.D. Su, Next-generation multi-crystalline silicon solar cells: 
Diamond-wire sawing, nano-texture and high efficiency, Sol. Energy Mater. Sol. Cells 141 (2015) 132-138. https://doi.org/10.1016/j.solmat.2015.05.030.

64 J. Oh, H.C. Yuan, H.M. Branz, An 18.2\%-efficient black-silicon solar cell achieved through control of carrier recombination in nanostructures, Nat. Nanotechnol. 7 (2012) 743-748. https://doi.org/10.1038/NNANO.2012.166.

65 K.X. Chen, Y.Y. Liu, X.S. Wang, L.J. Zhang, X.D. Su, Novel texturing process for diamond-wire-sawn singlecrystalline silicon solar cell, Sol. Energy Mater. Sol. Cells 133 (2015) 148-155. https://doi.org/10.1016/j.solmat.2014.11.016.

66 Y.T. Cheng, J.J.Ho, S.Y.Tsai, Z.Z. Ye, W. Lee, D.S. Hwang, S.H. Chang, C.C. Chang, K.L. Wang, Efficiency improved by acid texturization for multi-crystalline silicon solar cells, Sol. Energy 85 (2011) 87-94. https://doi.org/10.1016/j.solener.2010.10.020.

67 M.J. Stocks, A.J. Carr, A.W. Blakers, Texturing of polycrystalline silicon, Sol. Energy Mater. Sol. Cells 40 (1996) $33-42$. https://doi.org/10.1016/0927-0248(95)00077-1.

68 D. Kumar, S.K. Srivastava, P.K. Singh, M. Husain, V. Kumar, Fabrication of silicon nanowire arrays based solar cell with improved performance, Sol. Energy Mater. Sol. Cells 95 (2011) 215-218. https://doi.org/10.1016/j.solmat.2010.04.024.

69 G. von Gastrow, R. Alcubilla, P. Ortega, M. Yli-Koski, S. Conesa-Boj, A. Fontcuberta i Morral, H. Savin, Analysis of the Atomic Layer Deposited Al2O3 field-effect passivation in black silicon, Sol. Energy Mater. Sol. Cells 142 (2015) 29-33. https://doi.org/10.1016/j.solmat.2015.05.027.

70 B. Sopori, S. Devayajanam, S. Shet, D. Guhabiswas, P. Basnyat, H. Moutinho, L. Gedvilas, K. Jones, J. Binns, J. Appel, Characterizing Damage on Si Wafer Surfaces Cut by Slurry and Diamond Wire Sawing, 2013 39th Photovoltaic Specialists Conference (PVSC) (2013) 0945-0950. https://doi.org/10.1109/PVSC.2013.6744298.

71 H. Park, J.S. Lee, S. Kwon, S. Yoon, D. Kim, Effect of surface morphology on screen printed solar cells, Curr. Appl. Phys. 10 (2010) 113-118. https://doi.org/10.1016/j.cap.2009.05.005.

72. C. Modanese, H. Laine, T. Pasanen, H. Savin, and J. Pearce, Economic Advantages of Dry-Etched Black Silicon in Passivated Emitter Rear Cell (PERC) Photovoltaic Manufacturing, Energies, 11(9) p. 2337, (2018). https://doi.org/10.3390/en11092337 